\title{
Surgical revascularization in acute coronary syndrome patient after failed PCI with broken angioplasty wire protruding into aortic root.
}

\author{
Tomasz Urbanowicz ${ }^{1}$, Anna Olasinska-Wisniewska ${ }^{1}$, Bartłomiej Perek ${ }^{1}$, and Marek \\ Jemielity $^{1}$ \\ ${ }^{1}$ Poznan University of Medical Sciences
}

June 29, 2020

\begin{abstract}
Percutaneous coronary interventions (PCI) have an established position in the management of patients presenting with acute coronary syndromes and stable coronary artery disease with low complications rates. We present the case of a 67-year-old male referred for urgent coronary catheterization intervention with anterior wall ST-elevation myocardial infarction diagnosis. After stent implantation, the wires were removed however a part of the wire was entrapped in the coronary artery. The metallic coil covering the core of the angioplasty wire was left in proximal part of LAD and protruded into the aortic root. Patient was referred for emergency surgical procedure that was performed through median sternotomy in cardiopulmonary bypass (CPB) and moderate hypothermia. After transverse aortotomy, the foreign body of $7 \mathrm{~cm}$ in length was found irremovable, it was transected and left in the proximal portion of the left main coronary artery (LM). The decision to perform revascularization of LAD, CX and RCA was undertaken. The estimated graft blood flow measurements were satisfactory with the values of 7 $\mathrm{mL} / \mathrm{min}$ in LIMA-to-LAD graft, $39 \mathrm{~mL} / \mathrm{min}$ in SVBG-to-CX and $43 \mathrm{~mL} / \mathrm{min}$ in SVBG-to-RCA, respectively. The patient's postoperative course was uneventful. Cardiac surgery is a reasonable method of treatment in patients with coronary artery disease and PCI complicated with entrapment of broken guidewire protruding in aortic root.
\end{abstract}

\section{Hosted file}

PCI complications submission.3.doc available at https://authorea.com/users/337664/articles/ 463279-surgical-revascularization-in-acute-coronary-syndrome-patient-after-failed-pciwith-broken-angioplasty-wire-protruding-into-aortic-root 


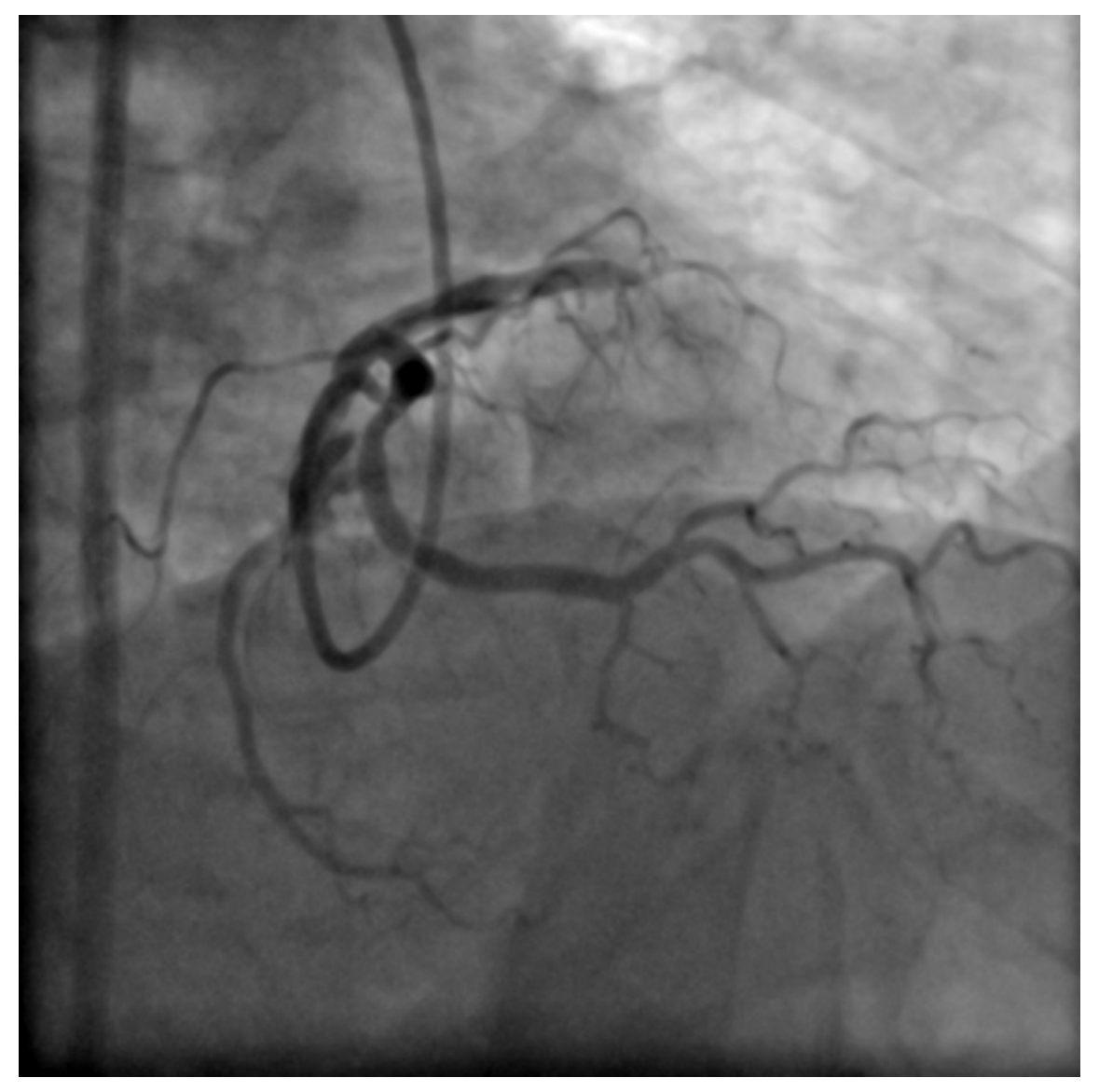




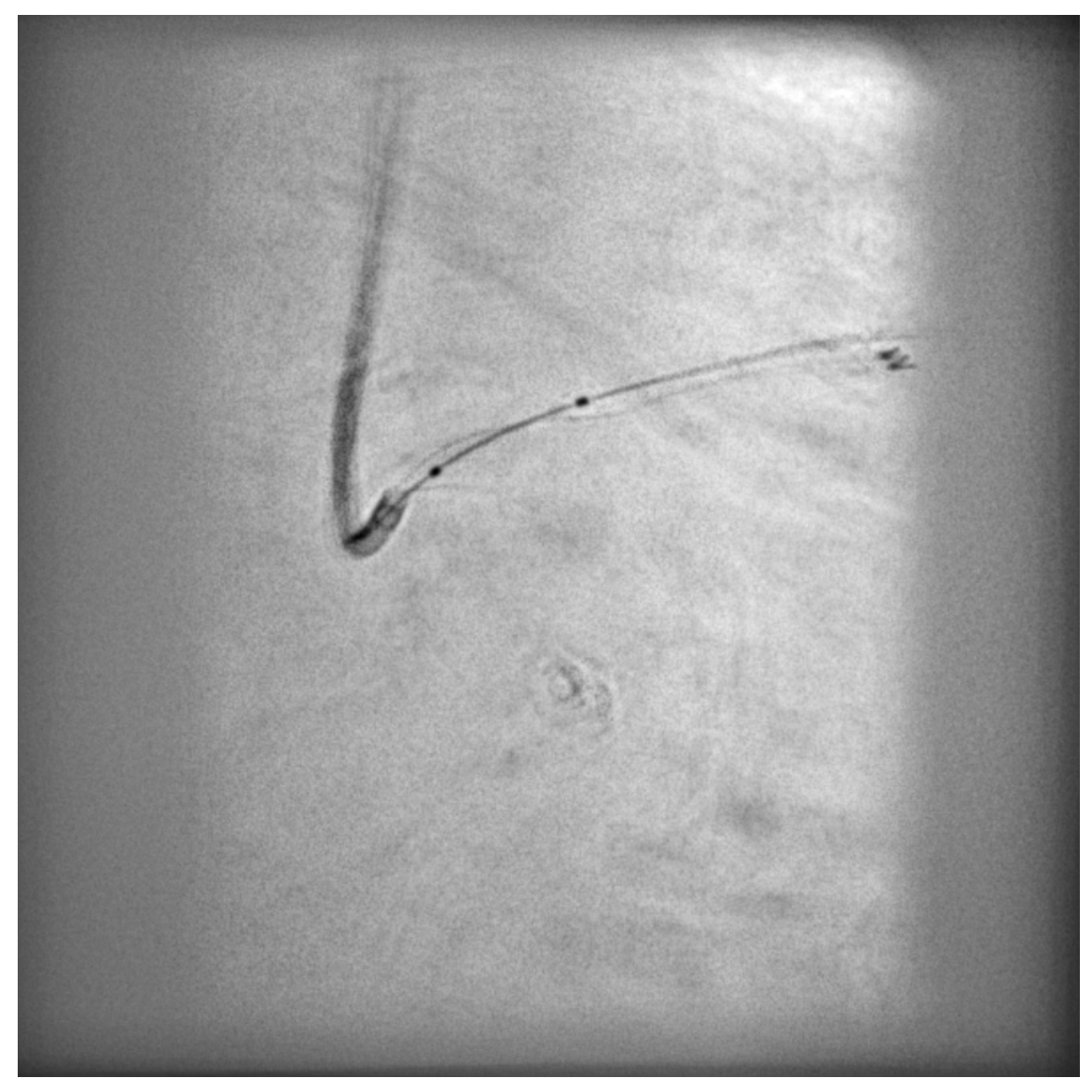




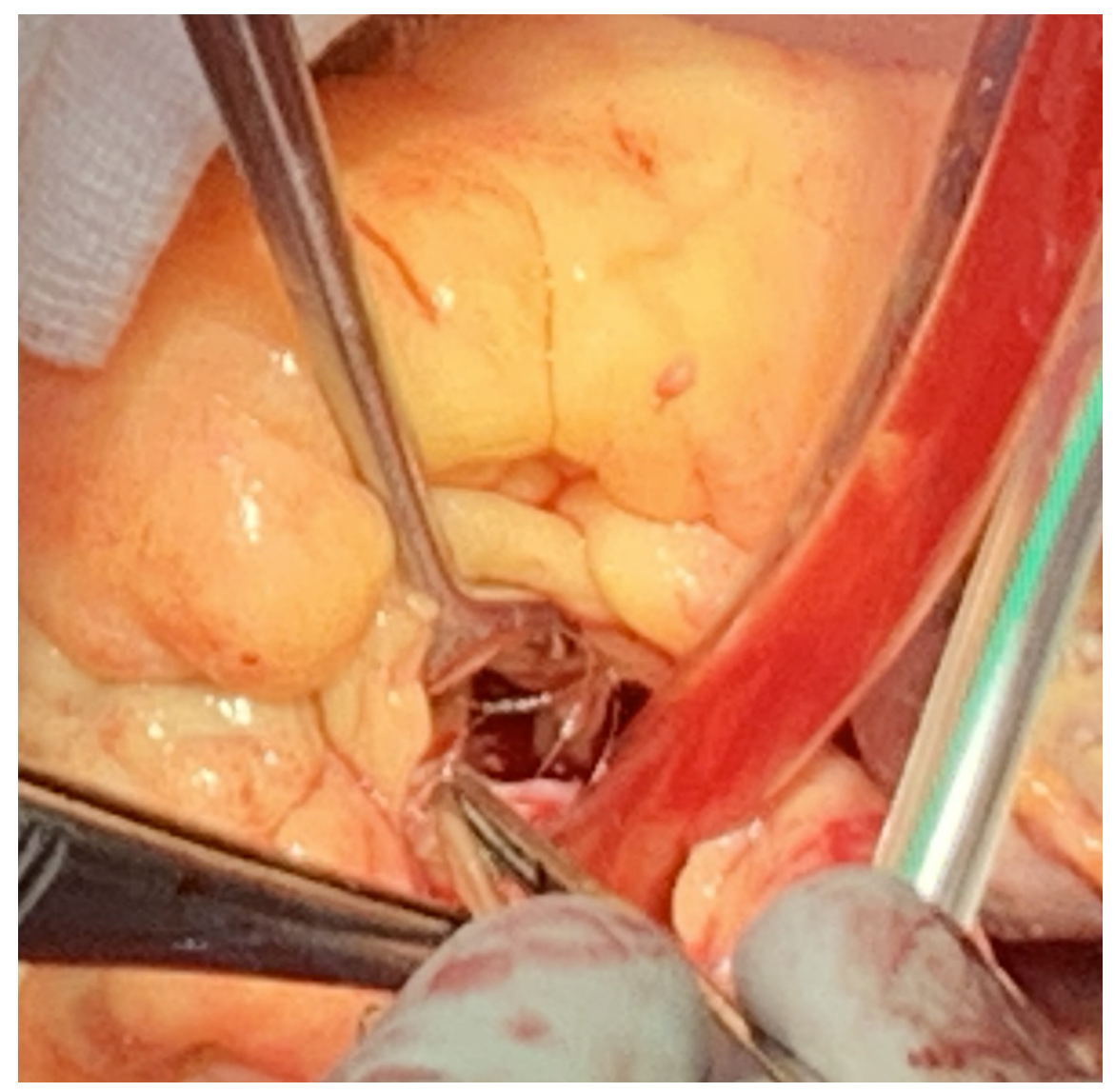

